\title{
Pedagogia freireana na perspectiva da educomunicação popular
}

Merli Leal Silva ${ }^{1}$

\section{Resumo}

Este artigo aborda os pressupostos da educomunicação e analisa sua relação com a pedagogia de Paulo Freire. A questão-problema é definir como a concepção de educomunicação de Mario Kaplún se relaciona com os princípios da pedagogia dialógica, crítica e emancipatória de Paulo Freire. O artigo faz uso da técnica de pesquisa bibliográfica e documental. Também contribuíram para a escrita do artigo, as ações de educomunicação popular realizadas com a comunidade. Não é um estudo comparativo, mas sim uma reflexão sobre como a educação popular está presente nos projetos de educomunicação, considerando que o conteúdo é construído a partir da problematização do sujeito ou da comunidade. A realidade vivida na luta cotidiana é tema gerador, relevante e base de uma ação de educomunicação popular.

\section{Palavras-chave}

Educação crítica. Educomunicação popular. Pedagogia freireana. Método de ensino.

1 Pós-doutora em Educomunicaçao pela Universidade Federal do Rio Grande do Sul, Brasil; professora na Universidade Federal do Pampa, Campus São Borja, Rio Grande do Sul, Brasil. E-mail: merlileal@gmail.com. 


\title{
Freire's pedagogy in the perspective of popular educommunication
}

Merli Leal Silva ${ }^{2}$

\begin{abstract}
This article approaches the presuppositions of educommunication and analyzes its relation with the pedagogy of Paulo Freire. The problem question is how Mario Kaplun's conception of educommunication relates to the principles of Paulo Freire's dialogic, critical, and emancipatory pedagogy. The article makes use of the bibliographical and documentary research technique. Also contributed to the writing of the article, the actions of popular education carried out with the community. It is not a comparative study, but a reflection on how popular education is present in education projects, considering that the content is constructed from the problematization of the subject or the community. The reality lived in the daily struggle is the generating, relevant theme and basis of an action of popular education.
\end{abstract}

\section{Keywords}

Critical education. Educommunication. Freirean pedagogy. Teaching method.

\footnotetext{
${ }^{2}$ Postdoctorate in Educommunication, Federal University of Rio Grande do Sul, State of Rio Grande do Sul, Brazil; professor at the Federal University of Pampa, São Borja Campus, State of Rio Grande do Sul, Brazil. Email: merlileal@gmail.com.
} 


\section{Introdução}

O artigo é relevante por abordar um tema atual e necessário: o uso da tecnologia da informação e comunicação no desenvolvimento de práticas de ensino inovadoras. Mario Kaplún e Paulo Freire pensaram na comunicação e na educação como algo integrado, pois não há como educar sem comunicar. Há um emissor, um receptor, um código, um canal e uma mensagem, tanto no discurso educativo, quanto no comunicativo.

Paulo Freire é um educador atual e original que educou o povo para dizer a sua palavra. Atualmente, seus escritos têm motivado reflexões e debates nos meios de comunicação. Criticam a obra de Freire sem nunca tê-la lido. Contudo, percebe-se que sua epistemologia é referência em vários países.

Não há dúvidas: seus estudos sobre educação de adultos têm uma abordagem libertadora e baseada na conscientização das classes oprimidas. Para Freire (2005, p. 24) "não é a conscientização que pode levar o povo a fanatismos destrutivos. Pelo contrário, a conscientização, que lhes possibilita inserir-se no processo histórico, como sujeito, evita os fanatismos e os inscreve na busca de sua afirmação". Na verdade, a tomada de consciência abre caminho para a expressão da insatisfação social e a assunção de posturas rebeldes e de resistência. Entretanto, a classe dominante tem a seu serviço aparelhos ideológicos poderosos: educação (escola) e comunicação (meios de divulgação em massa).

Oposta à ideia de um mundo monolítico e uniforme, a educação popular postula educar com os oprimidos. Ninguém melhor que os excluídos e explorados para problematizar o seu cotidiano. Nesse sentido, a educação popular identifica o tema gerador das comunidades, e, a partir dele, constrói a "pauta" dos círculos de cultura (as aulas).

A conexão das ideias de Paulo Freire e Mario Kaplún fez nascer o campo da educomunicação. Conceitualmente, educomunicação é usar a força dos meios de comunicação comunitários para dar voz ao que a mídia de referência silencia. Trata-se de não reproduzir acriticamente o modelo dos meios de comunicação de massa hegemônicos. Como metodologia, seus pressupostos mudam o viés do discurso das mídias agregando o componente "consciência crítica".

Este artigo foi escrito por meio da pesquisa bibliográfica e documental. Os objetivos específicos analisam como a ação-reflexão-ação (práxis freireana) se constitui em elemento 
central nas ações educomunicativas emancipatórias. Nessa perspectiva, a metodologia freireana é referência fundamental para entender os processos de educação como prática de liberdade. É através da construção de conhecimento que descobrimos nosso lugar no mundo e nos tornamos seres políticos. A aprendizagem é tanto um fator como um produto do desenvolvimento. Nesse sentido, o conhecimento significativo não é cópia figurativa da realidade, ao contrário, é uma elaboração subjetiva que resulta em adquirir representações organizadas do real e para a criação de instrumentos formais de conhecimento.

Para a pedagogia crítica, ensinar não é transferir saber. Quem ensina aprende ao ensinar e quem aprende ensina ao aprender. A relatividade dos saberes é definida por Freire como nossa capacidade em aprender com o outro, pois é na interação social e na troca de experiências que ampliamos nosso campo de visão. Não há consciências vazias, os homens humanizam o mundo através do diálogo, da comunicação e da luta coletiva. Mais do que aprender conteúdos, o oprimido necessita ser livre, consciente e autônomo, cônscio da missão no mundo.

Freire et al. (1981) postula uma pedagogia do oprimido, alicerçada pela luta política que impulsiona a busca da consciência crítica. Nesse sentido, vale referir os estudos do educador Álvaro Borges Vieira Pinto (1909-1987), grande inspiração para Paulo Freire. Eles se encontraram no Chile, ambos exilados pelo golpe de 1964. Há uma grande similaridade nas propostas educativas de ambos.

Segundo Mainardes (2015), em seu estudo sobre as ideias pedagógicas do autor, para Viera Pinto, a concepção ingênua e crítica são fundamentais para entender o sistema educativo, através de sua dimensão prático-pedagógica. Aproximando-se de Freire, considera que a perspectiva ingênua vê o educando como destituído de saber, e, tal como Kaplún e Freire, não sujeito, mas objeto da educação. Considera, assim, o educador um mero transmissor de uma mensagem que tem a verdade e o saber absoluto. A consciência ingênua concebe a educação a partir do poder simbólico da classe dominante. Por outro lado, a concepção crítica considera que a educação tem um teor político e transformador (MAINARDES, 2015). Nesse sentido, o educando tem em si o conhecimento e o desconhecimento, reforçando seu papel de sujeito da educação, em que, na verdade, as suas experiências de vida antes de escola são conhecimentos de base e devem ser valorizados. Perceber que ensinamos e aprendemos o tempo todo, em todo lugar, é um pressuposto das pedagogias emancipatórias. 


\title{
Kaplún e Freire: educomunicação popular
}

A educomunicação popular tem como principal referencial teórico o argentino Mario Kaplún (1923-1998), que cunhou o termo a partir de sua atuação como jornalista em comunidades empobrecidas, durante a ditadura militar argentina. $\mathrm{O}$ teor político e dialógico da educomunicação tem estreita relação com a obra de Paulo Freire, e o próprio autor disse ter o brasileiro como inspiração.

Um dos papéis da educomunicação é utilizar os recursos midiáticos e tecnológicos para colocar em "cena" os temas geradores da classe trabalhadora. Configura-se, assim, em um campo de conhecimento que desvela o poder da mídia com as classes populares. Elas se tornam, assim, responsáveis pela produção de seus próprios conteúdos, pois o debate no círculo de cultura critica os meios de massa, estes comprometidos com pautas que não as representam. Kaplún (2002) afirma que comunicação educativa é formativa e que os meios de comunicação são instrumentos de transformação social e contrainformação.

\begin{abstract}
¿Por qué empezar hablando de educación y no directamente de comunicación? ¿No es alargar el camino con un rodeo innecesario?

En primer lugar, cuando hacemos comunicación educativa estamos siempre buscando, de una y otra manera, un resultado formativo. Decimos que producimos nuestros mensajes "para que los destinatarios tomen conciencia de su realidad", o "para suscitar una reflexión", o "para generar una discusión". Concebimos, pues, los medios de comunicación que realizamos como instrumentos para una educación popular, como alimentadores de un proceso educativo transformador. (KAPLÚN, 2002, p. 15).
\end{abstract}

$\mathrm{Na}$ educomunicação popular, os processos ocorrem de forma horizontal, dialógica e emancipatória. O ponto de partida é a realidade dos sujeitos oprimidos, problematizada nos círculos de cultura e nos espaços formais e não formais de ensino. Nesse sentido, educar para os meios de comunicação é uma intervenção em todos os domínios da nossa existência individual e social, mediada pelas tecnologias. Nitidamente, as tecnologias digitais modificam o modo como produzimos o conhecimento, uma vez que as narrativas passam a ser instantâneas conectadas e abrangentes. É um modo de ensinar e aprender mais sensorial, questionador e desafiador.

É necessário reconhecer que os modos de produção de discursos midiáticos constituem conteúdo de ensino, configurando-se em uma estratégia cultural, orientada pelas linguagens audiovisuais e pela produção crítica de conteúdos. Isso significa proporcionar aos educandos 
atividades desafiadoras, experimentais, baseadas em resolução de problemas e projetos coletivos e solidários. As práticas de ensino se modificam através da ampliação dos pontos de vista e fontes experienciais diversas. Livros e professores deixaram de ser única fonte de conhecimento. Há uma rede de tecnologia da informação que comunica em massa conteúdos variados e persuasivos, para milhões de pessoas. O que é real e o que é fake news ${ }^{3}$ criada pelos meios de comunicação? Qual narrativa faz mais sentido no contexto em que as classes populares vivem? Afinal, quando as comunidades populares produzem uma notícia, uma propaganda ou um produto cultural, ela está capacitada a descobrir formas de interferir na disputa da narrativa dos conteúdos midiáticos.

Os meios de comunicação hegemônicos definem como contar determinado fato, sempre considerando (e priorizando) a classe que detém o poder econômico. Quando falamos, por exemplo, em favela, surge em nossa mente o imaginário criado pelas mídias sobre as comunidades: violência e vulnerabilidade social. No sistema capitalista, o discurso das grandes redes de comunicação representa os ricos. Sem uma visão dialética da realidade das comunidades oprimidas nas mídias, o resultado será sempre uma visão parcial e estereotipada, que não comunica que a favela é lugar de produção de existência, conhecimento e resistência.

Somos meio e mensagem e podemos produzir nossa própria visão de mundo, desmistificando temas e abordagens tendenciosas e parciais, muito comuns nas mídias transnacionais e corporativas. Assim, faz-se necessário construir um contradiscurso nos meios de comunicação populares, a partir dos temas geradores das comunidades oprimidas. Uma educação que pensa a comunicação como social, a crítica aos meios como fundamental e a produção autoral de conteúdo como civilizatória constituem-se uma trincheira contra a desinformação e a manipulação do sistema midiático. É outra forma de educar para a autonomia e a liberdade, desvelando discursos de dominação na TV, no rádio, nas redes sociais e nas multiplataformas digitais.

Chega-se, assim, em uma ação educomunicativa que escuta e dá voz à diversidade da escola pública, aquela em que a maioria da população estuda e aprende a conviver em sociedade. Para tanto, ação e reflexão são fundamentais. A educomunicação, inspirada na práxis

\footnotetext{
3 “'Fake News' em tradução literal significa "notícia falsa". O uso corrente que essas palavras têm tido atualmente não é, porém, uma relação direta entre notícia falsa e mentira. Alguns intelectuais apontam que estamos sob o domínio do 'pós-verdade', isto é, um momento em que notícias falsas são difundidas principalmente com o advento da internet - importando muito mais as crenças que se pretendeu solidificar do que a veracidade dos fatos em si” (POUBEL, 2018, grifos da autora).
} 
freireana, debate os meios e reflete sobre eles e age construindo, a partir da cultura, discursos e meios contra hegemônicos. Portanto, cabe-nos descrever como a práxis freireana se constitui em metodologia educomunicativa.

\section{A práxis freireana: ação, reflexão, ação}

O método freireano tem características nítidas de uma teoria de aprendizagem crítica e política: a ação concreta no mundo deve ser refletida e problematizada, para retornar ao mundo como prática social. Nesse sentido, somos feitos de ações e reflexões, de teoria e de prática, sendo o saber relativo e provisório.

Pela educação popular, busca-se superar os saberes fragmentados e parciais, resultantes de experiências de exclusão, invisibilidade e opressão. Aprender e ensinar são atos complexos, que envolvem vários aspectos sociais, emocionais, orgânicos e estruturais.

Para Freire et al. (1981), há três premissas para ensinar de forma emancipatória: 1) alcançar uma compreensão dos mecanismos de base que explicam o funcionamento da realidade social; 2) favorecer uma aquisição de conhecimentos úteis ao processo de transformação dessa realidade; 3) permitir um trabalho no nível das estruturas de pensamento e de linguagem, com ênfase particular nas questões que perpassam a produção da existência do educando, contribui sobremaneira para criar vínculo afetivo e confiança no educador. Saber qual a trajetória do aluno, seu contexto de vida e realidade social é importante para a criação de estratégias que contribuam para o educando tomar posse da realidade, de forma crítica.

Assim também ocorre com a educomunicação, que não é uma técnica, mas uma postura epistemológica que traz o conteúdo cotidiano da comunicação para ser desvelado e recriado na sala de aula. Problematizar uma notícia de jornal e, a partir daí, criar seu próprio jornal são formas de transformar a educação em educomunicação.

Para Freire (1980), problematizar os temas que nos afastam de sermos mais é base para o processo de conscientização. Ele afirma que

Procurar um tema gerador é procurar o pensamento do homem sobre a realidade e a sua ação sobre esta realidade que está em suas práxis. $\mathrm{Na}$ medida em que os homens tomam uma atitude ativa na exploração de suas temáticas, nessa medida sua consciência crítica da realidade se aprofunda e anuncia estas temáticas de realidade. (FREIRE, 1980, p. 32). 
Os educandos, mais do que receber uma informação, analisam os aspectos de sua própria experiência existencial representada nos conteúdos de aprendizagem. Para Freire (1980), procurar o tema gerador é procurar o pensamento do homem sobre a realidade e a sua ação sobre esta realidade. Para ter valor, toda ação educativa deve ser precedida de uma reflexão sobre o contexto vivido, ou será apenas reduzir o educando a objeto. A rotina e a tradição tornaram a escola um espaço conservador e acrítico. Sempre há modelos a seguir, normas a cumprir, conteúdo a vencer, do jeito que o sistema definiu, sem contestar.

Uma sala de aula em 2019 é praticamente igual a uma sala de aula de 1819. A falta de projeto político para educar as pessoas é recorrente, ou melhor, há um projeto de formação vindo das elites e disseminado em massa para formar indivíduos sem voz, passivos e resignados. O cenário é ainda pior na escola pública, em que o professor não é valorizado e a formação de base é negligenciada.

Ensinar sobre o que é uma árvore de ipê, por exemplo, é complexo e desafiador. O aspecto dialógico do ensino crítico é transformar perguntas em outras perguntas e gerar reflexão e ação. Um ipê é muito mais que uma árvore, é sombra, descanso, infância, flores roxas e amarelas, árvore símbolo da região da fronteira gaúcha, alimento dos pássaros, a árvore dos livros do Érico Veríssimo. Ou como se planta um ipê, quanto tempo ela dura, como a poluição e o desmatamento destroem as florestas de ipê? Como o setor madeireiro lucra com a venda de árvores nativas? Quais as leis que protegem as florestas? Fotos e vídeos de ipês pelo mundo etc. O uso do som, da imagem, do audiovisual como estratégias educomunicativas transforma o conteúdo maçante em algo significativo e marcante. É a cultura popular servindo de base para o ensino contextualizado e libertador.

Freire (1980) descreve bem o método de educação popular:

O importante é advertir que a resposta que o homem dá a um desafio não muda só a realidade com a qual se confronta: a resposta muda o próprio homem, cada vez um pouco mais, e sempre de modo diferente. Pelo jogo constante destas respostas o homem se transforma no ato mesmo de responder. (FREIRE, 1980, p. 37).

\section{A aprendizagem sob o ponto de vista freireano}

A premissa básica de Paulo Freire é que os saberes são relativos. Aprendemos e ensinamos na mesma medida, uma vez que trazemos vivências e experiências cotidianas que se constituem 
em saberes. Cai por terra a ideia de um professor que sabe tudo e que desconsidera o saber popular e a vida real da comunidade onde atua. Educar é uma intervenção social de alta complexidade, que exige humildade e amorosidade. A comunidade, ao ter como tema de estudo sua problemática de vida, se conscientiza de que produz conhecimento e também ensina. Na maioria das vezes, estudar é algo penoso para a maioria dos jovens.

Quando questionamos professores sobre suas metodologias, Paulo Freire não entra em nenhum momento. Na verdade, percebe-se que educadores e educadoras com formação em licenciaturas sabem muito pouco sobre ele. O que Freire propõe como método é simples: observar a realidade, escutar com atenção os educandos, elaborar com eles temas de estudo que os motivem a pensar o mundo a partir da problematização da realidade. $O$ grande salto civilizatório de Freire é ouvir o aluno, construir com ele conhecimento - aprendendo com ele. Quando um professor diz para um aluno “Obrigado por me ensinar algo novo", está praticando Paulo Freire.

A proposta pedagógica de Paulo Freire nasce da luta social, portanto o espaço educativo é mais do que escola formal. Ao realizar um projeto educomunicativo popular, antes de tudo, deve-se conhecer a comunidade e seu contexto social, econômico, cultural, familiar, enfim, mergulhar na realidade oculta que pode desvelar os temas geradores do grupo. O objetivo da educação popular é superar o saber fragmentado, descolado da realidade, alienador e que busca se conformar ao que está posto (FREIRE et al., 1981). Em função dessa superação, surge um conteúdo para ser debatido e problematizado, de forma horizontal e na ação coletiva. O mesmo ocorre quando usamos a força da educomunicação popular, nascida nos movimentos sociais, nas comunidades oprimidas e nos espaços alternativos e democráticos, para mostrar outras representações sociais.

\section{Pesquisa como itinerário didático para produzir conteúdos}

Para Freire e Kaplún pesquisar é investigar as situações reais e vividas pelo educando para alcançar um quadro de referência. Pode ser entendida também como o estudo de temas significativos para uma experiência de ensino-aprendizagem que visa compreender a realidade social. Além disso, contribuir para adquirir conhecimentos úteis ao processo de transformação dessa realidade e permitir um trabalho em nível das estruturas de pensamento e de linguagem. 
É fundamental perceber que o método de Freire tem raízes na educação popular, portanto, é uma proposta educativa para a classe trabalhadora, oprimida e, de certa forma, expulsa da escola tradicional, pois sua realidade não é levada em conta para criar os planos de ensino. Similarmente, Kaplún construiu pautas jornalísticas e notícias com as comunidades populares da Argentina, inspiradas na sua realidade.

O itinerário proposto por Freire é facilmente adaptado ao contexto educomunicativo, pela conexão de abordagens e práticas pedagógicas. A forma de criar projetos educomunicativos segue o mesmo roteiro, com algumas adaptações bem pontuais. É primordial considerar a experiência prévia dos educandos e construir com eles, contudo, há um itinerário previamente definido por Freire et al. (1981) conforme se observa a seguir.

Definir objetivos: construir com o educando o motivo da intervenção. O que é relevante para ele resolver? Uma roda de conversa ou uma sessão individual dialogada faz brotar muitos desejos em forma de objetivos. Onde eu quero chegar aprendendo a ler? Ou aprendendo trigonometria? Qual o significado desse conhecimento na minha vida? Vale a pena criar um canal de comunicação? Qual o meio de comunicação que representaria a comunidade?

Histórias de vida e plano de trabalho: cada educando conta oralmente as histórias de vida e depois escreve. Diz o que espera do trabalho educativo. As narrativas individuais encontram pontos de contato com narrativas de outros educandos: reprovações, baixa autoestima, falta de estímulos para aprender, migração do campo para a cidade, falta de recursos da família. Criase das histórias individuais um quadro com as histórias coletivas, servindo como espelho e apoio (somos muitos). Do debate, surgirão os temas mais relevantes e prioritários para estudo. Freire os chama de temas geradores.

Estudo do tema gerador: o tema gerador é decomposto em subtemas. Tematizar é construir uma narrativa que abarque sua realidade, para que ela possa ser problematizada. Como as coisas são assim e como podemos mudá-las para que possamos ser mais felizes e plenos de direitos? O mundo está sendo, nunca estará pronto se os sujeitos não estão conscientizados da realidade que pode ser cruel, mas também pode ser modificada. A participação popular, de forma representativa e democrática, é um dos caminhos possíveis para reverter a alienação imposta por um sistema excludente, capitaneado por mídias hegemônicas que ocultam a realidade. Ou melhor, criam uma realidade paralela. 
Síntese e relatório: avaliar percurso, autoavaliação e reconhecimento das possibilidades de transformação da realidade, seja ela qual for. O que se busca é fornecer os instrumentos e competências que são desejáveis pela escola e, ao mesmo tempo, a crítica de sua utilização numa perspectiva coletiva.

Os passos descritos servem como proposta de rota. Ajudam a organizar o processo de aprendizagem como um grande desafio, único e com a intenção de tornar o educando protagonista do seu conhecimento. $\mathrm{O}$ mais importante é que ele possa desvelar a realidade vivida nos conteúdos de ensino, para que estes possam ser significativos e não apenas reprodução de um saber da classe dominante.

\section{Paulo freire: conexões com a educomunicação}

Cada pessoa deve se enxergar como um portfólio de habilidades, experiências e realizações, algo como um resumo ambulante. A tecnologia em educação não se restringe apenas a redes digitais. Paulo Freire, em 1964, utilizava dispositivos para projetar imagens da comunidade com o intuito de debater os temas geradores. Seu método busca as imagens do cotidiano do educando como forma de projetar a experiência vivida e contemplada pelo olhar de quem as vive. Vivemos o século das imagens em movimento, produzidas a partir do nosso olhar. Freire utiliza recursos midiáticos da época: retroprojetor, diapositivos, monóculos e rádio, conectado aos princípios da educomunicação.

Em 1962, Paulo Freire alfabetizava usando os recursos imagéticos da época. A cartilha criada (Figura 1) por Freire foi ilustrada com imagens construídas com a comunidade aprendente. Igualmente, os temas de estudo foram organizados a partir do diálogo e debate com os trabalhadores. O resultado foi uma alfabetização que fez os trabalhadores realizarem a leitura crítica do mundo que os cercava. 
Figura 1 - Imagens da comunidade aprendente

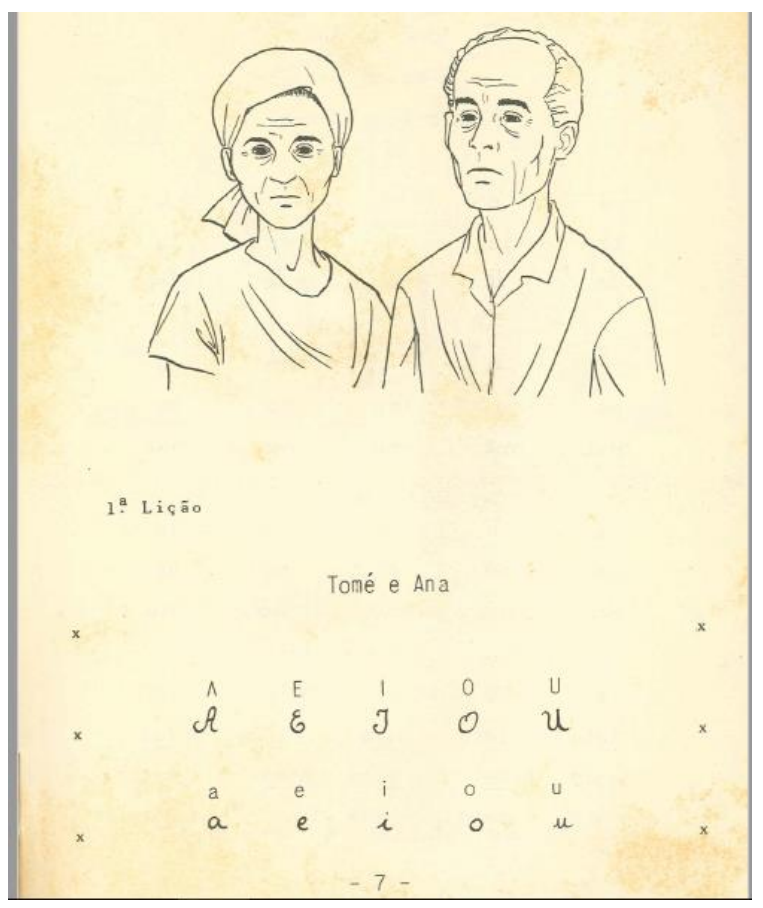

Fonte: Trancoso (1962).

As histórias que a cartilha conta (Figura 2) partem do universo da comunidade, que elencou quais histórias faziam sentido de serem contadas.

\section{Figura 2 - Cartilha}

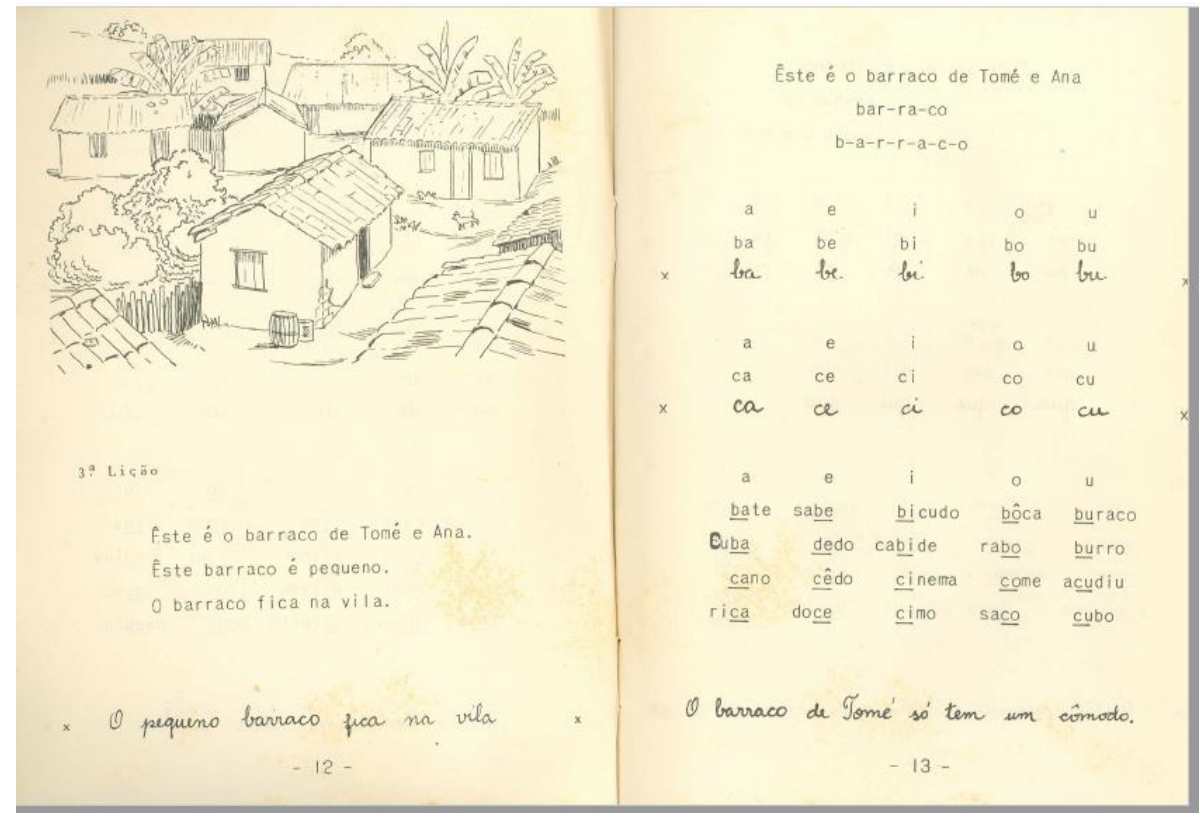

Fonte: Trancoso (1962). 
Ao problematizar a realidade vivida (Figura 3) eles podiam escrever outra versão da história, agora com o protagonismo da classe popular.

Figura 3 - Problematização da realidade

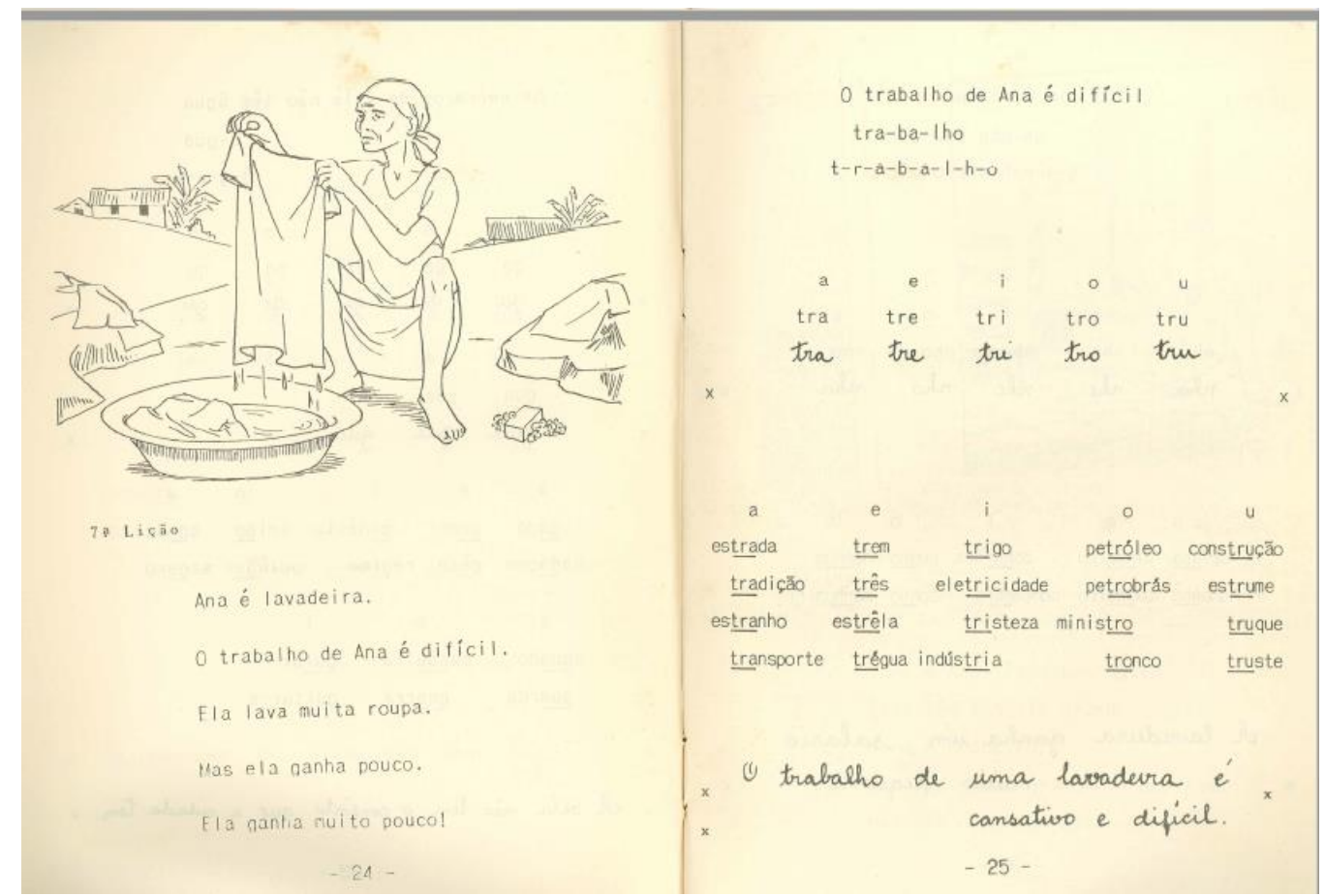

Fonte: Trancoso (1962).

\section{Considerações finais}

O objetivo deste artigo foi descrever as conexões entre a pedagogia de Paulo Freire e a educomunicação popular, de Mario Kaplún.

No contexto educativo, Paulo Freire criou um método humanizador, calcado em ações didáticas ativas, inovadoras, sensíveis e inspiradas na realidade da classe popular. Sua vasta obra tem como mérito principal fazer refletir sobre o papel da educação na reprodução de desigualdades e, paradoxalmente, como ela pode ser libertadora. A mesma concepção norteia o trabalho de educomunicação popular, do argentino Mario Kaplún. É uma alfabetização midiática, na qual o debate para a busca do tema gerador parte da mídia hegemônica e sua crítica a ela. Se aprendermos a ler e escrever, podemos igualmente aprender a entender o mecanismo de produção de sentido dos meios de comunicação. 
Freire e Kaplún são, sem dúvida, educadores e sedutores, manejam linguagens audiovisuais que prendem a atenção e potencializam a reflexão. A proposta dialógica e emancipatória da educomunicação é construir um itinerário de busca por conhecimento crítico. A leitura do mundo precede a leitura da palavra, e a leitura crítica dos meios de comunicação precede a produção de conteúdos contra hegemônicos.

Escolas de todos os níveis de ensino deveriam inserir educomunicação em seus projetos pedagógicos. Para os oprimidos, a escola ainda é uma esperança de dias melhores, e Freire e Kaplún mostram como podemos lutar sendo educadores/educomunicadores críticos e sensíveis. O professor é um intelectual orgânico e pode melhorar a sociedade através da sua práxis educativa. Precisamos, urgentemente, debater com as comunidades educativas a necessidade de aprender a fazer leitura crítica dos meios de comunicação e produzir conteúdo educativo autoral. Há uma geração com acesso ilimitado aos meios de comunicação, contudo, os docentes ainda não foram devidamente preparados para utilizar a mediação tecnológica para ensinar e aprender.

A escola pública, por não ter recursos, acaba negligenciando o espaço laboratorial de tecnologia. As escolas possuem os computadores, mas não a rede de comunicação e suporte técnico, o que inviabiliza o uso das máquinas, que ficam obsoletas. Ainda assim, mesmo sem máquinas ou rede, é possível produzir meios midiáticos que representam as temáticas da comunidade escolar.

A mídia de massa, em um mundo cada vez mais conectado, está perdendo espaço, em função da forma individual como as pessoas buscam informações. É socialmente importante que a educomunicação popular fomente a criação de "ecossistemas comunicativos", termo usado por Martín-Barbero (2002, p. 54) para representar a intensa transformação na sociedade contemporânea. O autor define dois movimentos nos ecossistemas comunicativos: 1) a materialização do ecossistema que se dá pela relação com as tecnologias; 2) a dinâmica da comunicação, representada pelos grandes meios e além deles. É um ambiente de informação e de conhecimentos múltiplos, não centrados, como o ambiente escolar tradicional, que usa basicamente o livro.

Contudo, cabe salientar que usar recursos de tecnologia não se configura em ação educomunicativa. É necessário compreender de forma crítica como o uso das tecnologias impacta nossa vida em sociedade e como podemos usar pedagogicamente os meios de 
comunicação. A educomunicação é, segundo Soares (2002), um conjunto de ações inerentes ao planejamento, implementação e avaliação de processos, programas e produtos com a finalidade de criar e fortalecer ecossistemas comunicativos em espaços educativos diversos. Além disso, ela melhora a comunicação das ações educativas e do uso das ferramentas tecnológicas. Como seu víeis teórico metodológico é freireano, tem uma função de conscientizar a classe popular por meio dos meios de comunicação e informação.

Freire e Kaplún são autores relevantes, sobretudo, se considerarmos o papel da educação popular na sociedade tecnológica de hoje. Há muita informação circulando nas redes, contudo, os meios de comunicação hegemônicos seguem selecionando as pautas e temas que podem "melindrar" a classe dominante. O que esses autores propõem é uma mudança ideológica na forma de produzir mensagens, considerando o contexto educativo e comunicativo das comunidades populares. É uma educação voltada aos adultos, que, em processo de busca do ser mais, enxergam na educação popular e midiática uma forma de divulgar a realidade oculta pelo poder político e simbólico das classes dominantes.

A educomunicação é um instrumento poderoso, que estimula a consciência crítica dos educandos. Faz-se necessário que os espaços de educação usem os suportes comunicativos e tecnológicos para que outros discursos e narrativas circulem, mobilizando a classe popular a dizer a sua palavra para ser finalmente escutada. A reflexão crítica sobre o poder da comunicação na vida cotidiana desvela mitos e contribui para a construção de uma sociedade solidária, dialética, plural e que apresenta, enfim, a sua narrativa.

\section{Referências}

FREIRE, P. et al. Vivendo e aprendendo: experiências do Idac em educação popular. São Paulo: Brasilense, 1981.

KAPLÚN, M. Una pedagogía de la comunicación (el comunicador popular). La Habana: Editorial Caminos, 2002.

MAINARDES, J. Álvaro Vieira Pinto: uma análise de suas ideias pedagógicas.

Laplage em Revista, Sorocaba, v. 1, n. 3, p. 98-117, set-dez. 2015. Doi: 10.24115/S2446622020151378p.98-117.

MARTÍN-BARBERO, J. Retos culturales de la comunicación a la educación. Elementos para uma reflexión que está por comenzar. Reflexiones Academicas, Santiago, n. 12, p. 45-57, 2000 . 
TRANCOSO, M. Uma família operária: manual de alfabetização para adultos e adolescentes. Belo Horizonte: Centro Popular de Cultura, 1962.

POUBEL, M. Fake news e pós-verdade. InfoEscola, Sociedade, 26 fev. 2018. Disponível em: https://www.infoescola.com/sociedade/fake-news. Acesso em: 21 mar. 2019.

SOARES, I. O. Gestão comunicativa e educação: caminhos da educomunicação. Comunicação \& Educação, São Paulo, n. 23, p. 16-25, jan.-abr. 2002. Doi: 10.11606/issn.2316-9125.v0i23p16-25.

Submetido em 11 de abril de 2019.

Aprovado em 21 de maio de 2019. 